\title{
Flame Heat Transfer between Parallel Panels
}

\author{
JOHN L. DE RIS and LAWRENCE ORLOFF \\ Measurements and Models Research, FM Global \\ 1151 Boston-Providence Turnpike \\ Norwood, Massachusetts 02062 USA
}

\section{ABSTRACT}

Flame heights and flame heat-flux distributions are measured for a wide range of fuels burning between two parallel panels. The flame heat flux levels are very sensitive to fuel sootiness. The heat flux distributions are obtained from the transient temperature rise of thermocouples peened into the steel parallel panel sidewalls. The measured flame heights imply an actual heat release rate per unit flame volume, $\dot{q}_{A}^{\prime \prime \prime}=1110 \mathrm{~kW} / \mathrm{m}^{3}$, consistent with literature values. This heat release rate per unit volume is independent of fuel type and fire scale. The heat flux distributions are integrated to obtain the net total heat transfer $\dot{Q}_{p}\left(\dot{q}_{0}^{\prime \prime}\right)$ to the panels above an arbitrarily specified panel heat loss rate, $\dot{q}_{0}^{\prime \prime}$. The integration is performed only over areas for which $\dot{q}_{f}^{\prime \prime}-\dot{q}_{0}^{\prime \prime} \geq 0$ to obtain the net heat transfer, needed by fire growth models. The results are described by a simple theoretical model that assumes heat transfer occurs only by radiation. The model gives the net heat transfer $\dot{Q}_{p}$ as a function the fire heat release rate, $\dot{Q}_{A}$, fuel smoke yield, $Y_{s}$, gas equivalent smoke yield, $Y_{g}$, parallel panel width, $w$ and separation, $d$, as well as the flame volumetric heat release rate, $\dot{q}_{A}^{\prime \prime \prime}$, and panel surface heat loss, $\dot{q}_{0}^{\prime \prime}$.

KEYWORDS: flame heat transfer, flame radiation, flame heights, parallel panel test

\section{NOMENCLATURE}

\begin{tabular}{|c|c|c|c|}
\hline$A$ & area $\left[\mathrm{m}^{2}\right]$ & Greek & \\
\hline$C_{S}$ & panel specific heat [kJ/kgK] & $\alpha$ & $=d / w$, aspect ratio [-- $]$ \\
\hline$d$ & panel separation [m] & $\beta_{1}$ & radiation constant $=1.04[--]$ \\
\hline$\ell_{f}$ & flame height [m] & $\beta_{2}$ & heat loss constant $=1.7$ [--] \\
\hline$\ell_{m}$ & mean beam length [m] & $\delta$ & panel thickness [m] \\
\hline$\dot{q}_{f}^{\prime \prime}$ & flame heat flux $\left[\mathrm{kW} / \mathrm{m}^{2}\right]$ & $\chi_{\mathrm{A}}$ & completeness of combustion [ --] \\
\hline$\dot{q}_{0}^{\prime \prime}$ & surface heat loss rate $\left[\mathrm{kW} / \mathrm{m}^{2}\right]$ & $\kappa$ & absorption coefficient $\left[\mathrm{m}^{-1}\right]$ \\
\hline$\dot{q}_{A}^{\prime \prime \prime}$ & $\begin{array}{l}\text { actual heat release rate per unit } \\
\text { volume }\left[\mathrm{kW} / \mathrm{m}^{3}\right]\end{array}$ & $\rho$ & panel density $\left[\mathrm{kg} / \mathrm{m}^{3}\right]$ \\
\hline$\dot{Q}$ & heat release rate $[\mathrm{kW}]$ & $\sigma$ & Stefan-Boltzmann $\left[\mathrm{kW} / \mathrm{m}^{2} \mathrm{~K}^{4}\right]$ \\
\hline$T$ & panel temperature & $\varsigma$ & dimensionless height [--] \\
\hline$T_{f}$ & effective flame rad. temp. [K] & \multicolumn{2}{|c|}{ Subscripts } \\
\hline$V_{f}$ & flame volume $\left[\mathrm{m}^{3}\right]$ & $A$ & actual \\
\hline
\end{tabular}




$\begin{array}{llll}w & \text { width of panels [m] } & f & \text { Flame } \\ Y_{s} & \text { smoke yield }[\mathrm{g} / \mathrm{g}] & p & \text { panel } \\ Y_{g} & \text { effect of gas }=0.01[\mathrm{~g} / \mathrm{g}] & T & \text { total }\end{array}$

\section{INTRODUCTION}

FM Global engineers have long favored the parallel panel geometry for evaluating the flammability of materials. The geometry provides a severe test. It is characteristic of high-piled and rack-storage of goods in warehouses. The flames tend to be confined by the two panels facing one another. This reinforces the heat transfer to the panel surfaces. Meanwhile the flames have ready access of air entering from the sides. The critical question addressed by a parallel panel test (with a given exposure fire) is whether a material will support runaway fire propagation. The parallel panel geometry is the reference geometry for FM Global's 4910 test protocol [1] for materials used in industrial clean rooms. Specifically, FM Global's 4910 Parallel Panel Test places two (0.6 meter wide by 2.4 meter high) panels of test material facing one another 0.3 meters apart and exposes them at their base to a $60 \mathrm{~kW}$ propane sand burner. There is the expectation that the parallel panel test geometry will eventually replace many costly full-scale fire tests of building materials (e.g., Room/Corner Tests, 25 ft. Corner Test, etc.). By adjusting its dimensions and exposure fires, the parallel panel concept can replicate a wide range of fire severities. It is also very economical in the use of test materials.

The parallel panel geometry is well suited for the development of simple engineering fire growth models based purely on laboratory property measurements. The present paper concentrates on an essential part of such models - namely - prediction of the net integrated flame heat transfer to the panels in terms of exposure fire heat release rate and properties of the wall material being tested. One needs a formula. More specifically, a formula for the net flame heat transfer to the walls, $\dot{Q}_{p}$ that depends on: (1) the actual chemical heat release rate, $\dot{Q}_{A}=\chi_{A} \dot{Q}_{T}$ of the fire, (2) the panel dimensions, (3) the flame sootiness, expressed as the smoke-point length (or equivalently, the smoke yield, $Y_{s}$ ), and (4) the surface heat loss rate, $\dot{q}_{0}^{\prime \prime}$ due to re-radiation from the wall material being tested. Using such a formula together with properties of the wall material, one should be able to predict whether a given exposure fire can induce uncontrolled fire growth in a Parallel Panel Test, [2]. Specifically, one wishes to determine

$\dot{Q}_{p}=\int_{A}\left(\dot{q}_{f}^{\prime \prime}-\dot{q}_{0}^{\prime \prime}\right)_{\dot{q}_{f}^{\prime \prime} \geq \dot{q}_{0}^{\prime \prime}} d A$

the total flame heat flux, $\dot{q}_{f}^{\prime \prime}$ exceeding a given (re-radiant) heat flux loss, $\dot{q}_{0}^{\prime \prime}$, integrated over that area, $A\left(\dot{q}_{0}^{\prime \prime}\right)$, of the side walls over which the flame heat flux exceeds the reradiant heat loss, $\dot{q}_{0}^{\prime \prime}$. It is this integrated heat flux, $\dot{Q}_{p}$, that can cause a test material to gasify and contribute its chemical heat to the fire.

Previously Ingason and de Ris [3] demonstrated that the flame heat flux is very sensitive to the fuel sootiness for parallel panel geometries. The present study extends those experimental results to a wider range of fuels and heat release rates using a very similar measurement method. The present study also goes further by providing an analytical 
model for the flame heat transfer, which is tailored for incorporation into parallel panel fire growth models applicable to wide ranges of fuels, fire scales and parallel panel geometries of different aspect ratios.
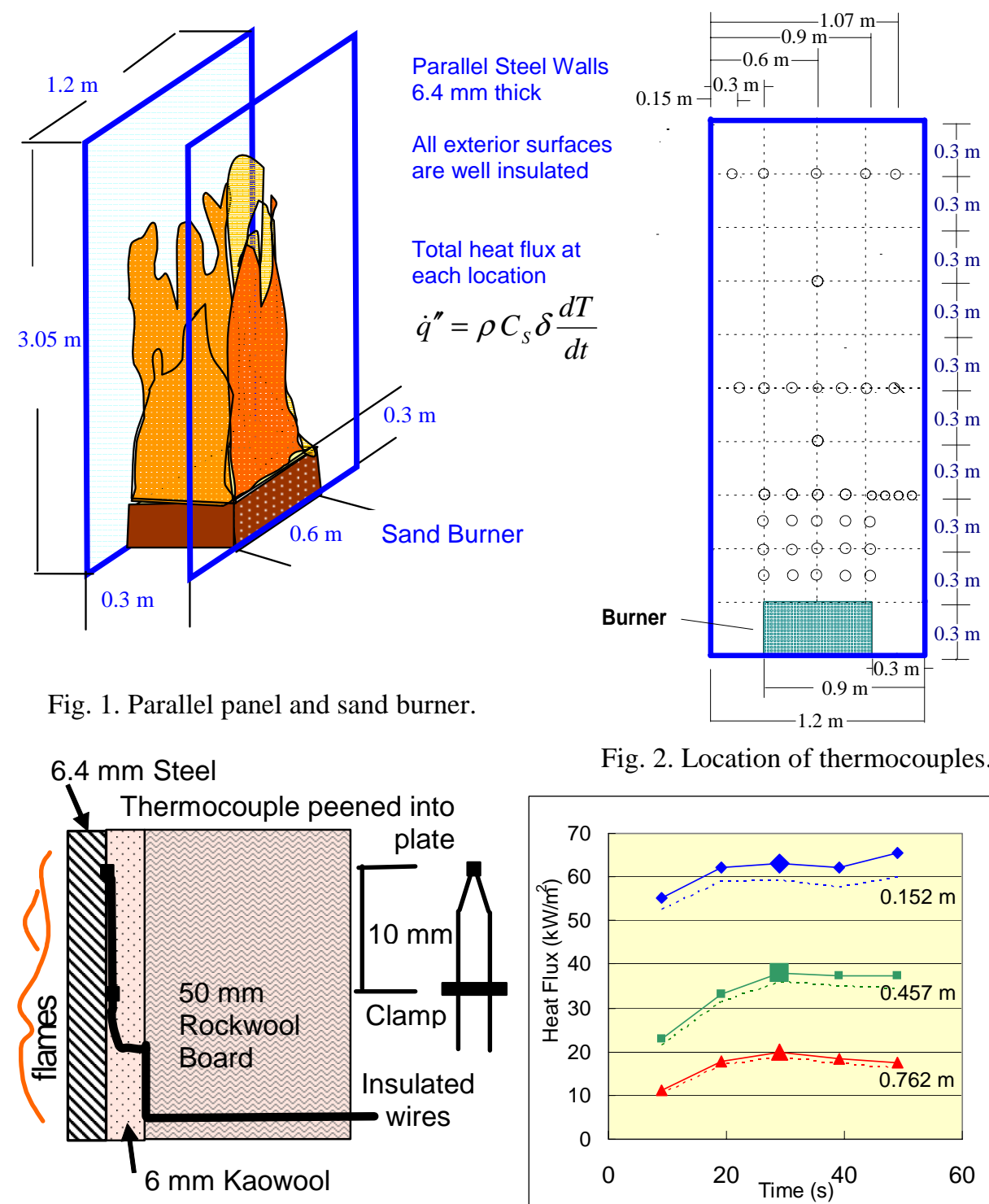

Fig. 2. Location of thermocouples.

Fig. 3. Thermocouple and insulation details.

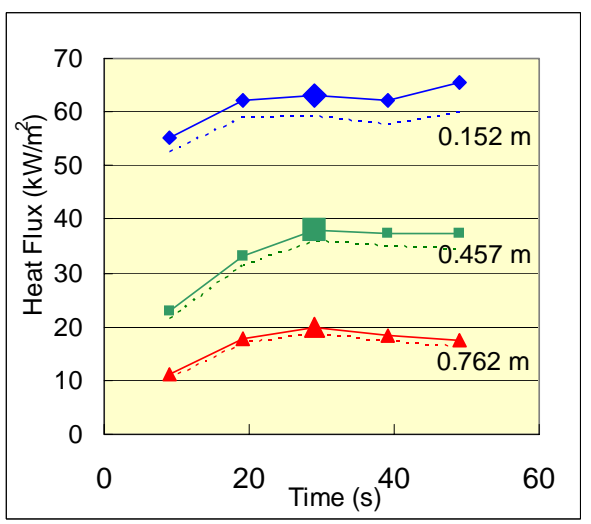

Fig. 4. Corrected transient heat flux.

\section{APPARATUS}

Figure 1 shows a general schematic of the apparatus. Gaseous fuels are supplied to the sand burner at the base of the panels. Flames are confined between two $6.4 \mathrm{~mm}$ thick carbon steel plates. Care is taken to seal the base of the panels to the sand burner to insure that all the air reaching the flames comes only from the open sides. Thermocouples are 
peened into both steel plates at the locations shown in Fig. 2. The thermocouple locations were chosen to provide 1) a detailed map of wall heat transfer distribution in the lower flaming region, 2) heat transfer variation with height on the burner centerline, and 3) the lateral profiles of heat transfer at the $4 \mathrm{ft}$. $(2.6 \mathrm{~m})$ and $8 \mathrm{ft}$. $(5.2 \mathrm{~m})$ elevations.

One sees from Fig. 1 that the panels are wider than the sand burner. The panels were originally constructed for another study. It makes little difference for the present study, -since the flames always remain within the width demarked by the sand burner.

Figure 3 shows the thermal insulation on the rear of the panels. It also shows how the thermocouples are peened and clamped to the panels. In order to protect thermocouple electrical insulation, the wall temperatures were never allowed to exceed $200{ }^{\circ} \mathrm{C}$. During the fire, the walls were soon blackened by the flames so that they had unit absorptivity to flame radiation. Prior to each test, all exposed wall surfaces were thoroughly vacuumed to remove fluffy soot accumulations that might interfere with the flame heat transfer.

\section{MEASUREMENTS}

The panels were initially at ambient temperature. The flames ignited and attained steady burning within 20 seconds. The heat transfer rate at each location was determined from the local rate of rise of the wall temperature. The heat transfer rate rose quickly to a maximum and then decreased slowly due to decreasing convective heat transfer from the flames and increasing radiant heat loss as the surface temperature increased. One is interested in the flame heat transfer to a surface at ambient temperature. To correct for the effect of increasing surface temperature, we added back both (1) the surface radiation assuming a unit emissivity and (2) the reduction in convective heat transfer assuming a convective heat transfer coefficient of $14 \mathrm{~kW} / \mathrm{m}^{2} \mathrm{~K}$. Taken together, the two corrections typically amounted to about $7 \%$ of the uncorrected rate of rise value. After correcting for these losses the flame heat transfer was became effectively constant. Figure 4 shows the transient heat flux together with corrections at three heights for a $102 \mathrm{~kW} \mathrm{C}_{3} \mathrm{H}_{6}$ fire. Calculations of heat losses (or gains) due to lateral conduction within the steel plates were always less than $1.5 \%$ of the measured flame heat transfer; while the heat losses through the rear insulation was less than and $0.5 \%$ of the measured heat transfer.

\section{Flame Heights}

Flame heights were measured for three of the fuels. See Fig. 5, below. Thirty photographs were analyzed for both the flame tip and continuous flame heights for each test. For sand burner heat release rates less than $100 \mathrm{~kW} / \mathrm{m}^{2}$, the flames appeared intermittent and are not reported here. The flame tip height, $\ell_{\text {tip }}$, is the highest location of a visible flame that is either attached to the main body of the flame or detached from the main body by no more than ten percent of its height. The continuous flame height, $\ell_{\text {cont }}$, is the maximum height at which the flames touch the walls on both sides. Between $\ell_{\text {cont }}$ and $\ell_{\text {tip }}$ the flames the flames became narrower and separated from the panels. Figure 5 shows correlation curves for both $\ell_{\text {cont }}$ and $\ell_{\text {tip }}$ based on data for all three fuels. Flame heights in general correlate better when plotted against actual heat release rates, $\chi_{A} \dot{Q}_{T}$, rather than theoretical heat release rates, $\dot{Q}_{T}$. This is because flame heights are governed principally by the amount of entrained air required to consume the supplied fuel. Actual 
heat release rates are more nearly proportional to oxygen consumption rates in the presence of incomplete combustion. Table 1, below, gives the values of $\chi_{A}$ for the fuels tested here.

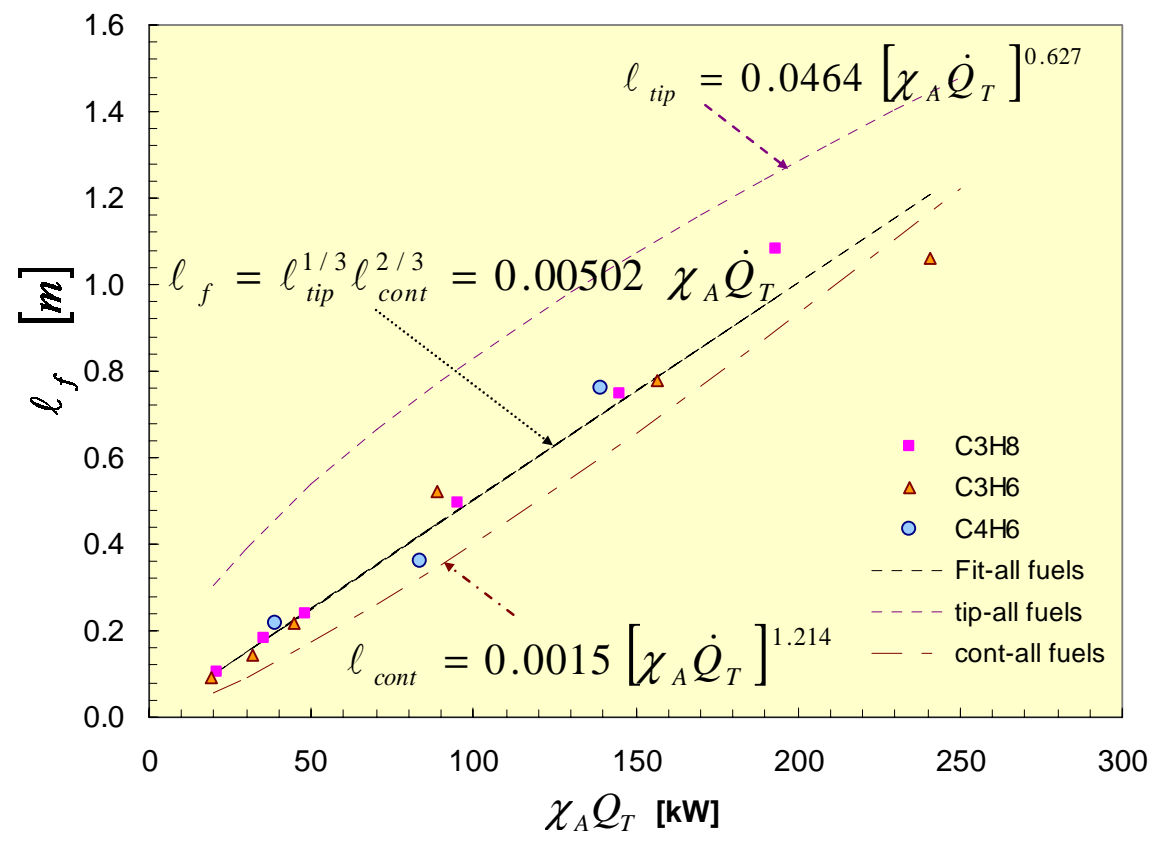

Fig. 5. Correlation of flame heights for all 3 fuels.

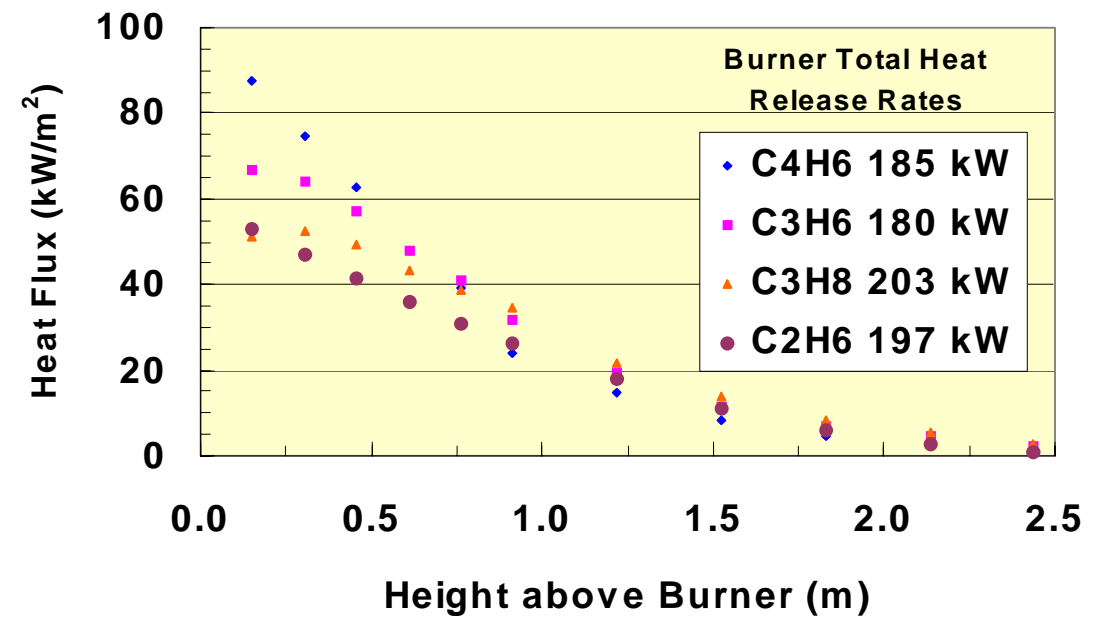

Fig. 6. Heat flux along panel centerline. 
Figure 5 also shows individual data points for the effective flame height, $\ell_{f}=\ell_{\text {tip }}^{1 / 3} \ell_{\text {cont }}^{2 / 3}$.

This definition is intermediate between $\ell_{\text {cont }}$ and $\ell_{\text {tip }}$. More specifically, it yields a flame height proportional to the actual heat release rate of the fire. Assuming the flames fully occupy the cross-section of the sand burner, $w d$, up to (but not beyond) the effective flame height, the flame volume is $V_{f}=w d \ell_{f}$. Using this definition the actual average heat release rate per unit volume for the fires becomes $1110 \mathrm{~kW} / \mathrm{m}^{3}$.

Previous experimental studies [4,5] found actual heat release rates per unit volume for buoyancy controlled turbulent fires are also independent of fire-scale. Photographic measurements [4] of flame volumes for 0.38 and $0.76 \mathrm{~m}$ diameter pool fires burning $\mathrm{CH}_{4}$, $\mathrm{C}_{3} \mathrm{H}_{8}$ and PMMA all yielded a volumetric heat release rate of $1200 \mathrm{~kW} / \mathrm{m}^{3}$. This latter value is close to the present value of $1110 \mathrm{~kW} / \mathrm{m}^{3}$. Scanning radiometer measurements [5] above of line and axisymmetric buoyant fuel jets show that the radiant output per unit flame volume is also independent of fire-scale for optically thin flames. These results are explained by the microscale combustion process being controlled by the Kolmogorov microscale which is virtually independent of scale for purely buoyant diffusion flames [6].

The present results for purely buoyant fires do not apply to situations where the turbulence is also generated by turbulent shear stresses that reduce the Kolmogorov microscale and thereby reduce the soot formation, flame radiation and smoke yield while increasing the volumetric heat release of the turbulent flames.

\section{Heat Flux}

Heat flux measurements on both panels were virtually identical. They were also reasonably symmetric across the width of each panel. Perhaps the extra width of the panels help shield and stabilize the flames. The measurements reported here have been averaged to take advantage of these symmetries. Figure 6 shows the centerline heat transfer measurements for four fuels having burner total heat release rates ranging from 180 to $207 \mathrm{~kW}$.

To evaluate the heat flux integral defined by Eq. 1, one must fit interpolating polynomials, $\dot{q}_{f}^{\prime \prime}(x, z)$, to the data in both vertical and lateral directions. The vertical distribution of heat flux, $\dot{q}_{f}^{\prime \prime}(o, z)$, along the centerline, was fitted by Padé functions, $g(z)$ comprising of ratios of polynomials taking either of the forms

$g(z)=\frac{a+c z+e z^{2}}{1+b z+d z^{2}}, \quad$ or $\quad g(z)=\exp \left[\frac{a+c z}{1+b z}\right]$

The use of ratios of polynomials, instead of ordinary polynomials, yielded smooth fits that are especially accurate near the ends of the fitted regions.

The lateral heat transfer profiles were close to Gaussian with almost all the heat transfer confined within the width, $w$ defined by the sand burner. Before fitting the lateral distributions the measured heat fluxes $\dot{q}_{f}^{\prime \prime}\left(x, z_{i}\right)$ at each height, $z_{i}$, were averaged four 
ways (left and right of centerline, front and back panels) to arrive at symmetric distributions. At each elevation the symmetric function was fitted to the measured lateral distribution of flame heat flux at each height, $Z_{i}$ where there were lateral thermocouples. The $H_{0}$ and $H_{2}$ functions, above, are the zero ${ }^{\text {th }}$ and $2^{\text {nd }}$ order Hermite polynomials. The function becomes truly Gaussian for $A_{2}=0$. It is symmetric and has zero derivative at $\mathrm{x}=0$. The fits are nearly Gaussian. That is, $A_{2} / A_{0}$ was small. The fitting process involved finding the optimum values of $A_{0}, A_{2}$ and $\sigma$ using an MS Excel optimization procedure.

$$
\begin{aligned}
& f(x)=A_{0} H_{0}(x / \sqrt{2} \sigma) \exp \left(-x^{2} / 2 \sigma^{2}\right)+A_{2} H_{2}(x / \sqrt{2} \sigma) \exp \left(-x^{2} / 2 \sigma^{2}\right) \\
& H_{0}(x)=1 ; \quad H_{2}(x)=4 x^{2}-2
\end{aligned}
$$

The vertical and horizontal interpolating functions were combined for each test to provide a smooth interpolation expression for the heat flux, $\dot{q}_{f}^{\prime \prime}\left(x, z_{i}\right)$, over the panel width,$w$. $\dot{Q}_{p}\left(\dot{q}_{0}^{\prime \prime}\right)$ was then evaluated, according to Eq. 1 , by integrating $\dot{q}_{f}^{\prime \prime}\left(x, z_{i}\right)-\dot{q}_{0}^{\prime \prime}$ wherever it is positive. Values of $\dot{Q}_{p}\left(\dot{q}_{0}^{\prime \prime}\right)$ were obtained for each of the tests for surface heat losses $\dot{q}_{0}^{\prime \prime}$ equal to $0.0,5.0,10,15,20,30 \mathrm{~kW}$. The data are too extensive to present here, however we note that the values of $\dot{Q}_{p}\left(\dot{q}_{0}^{\prime \prime}\right)$ decreases almost linearly with the assumed surface heat loss $\dot{q}_{0}^{\prime \prime}$. The data for $\dot{q}_{0}^{\prime \prime}$ equal to 5 and $15 \mathrm{~kW}$ are shown in Figs. 7 and 8 . The results correlate according to the model described below.

\section{MODEL}

We now develop a simple model for the flame heat transfer assuming that the heat transfer to the walls occurs only by radiation. Assume flames fully occupy the volume between the parallel panels up to height $\ell_{f}$ but not beyond. This yields a flame volume

$V_{f}=w d \ell_{f}=\dot{Q}_{A} / \dot{q}_{A}^{\prime \prime}$

where $\dot{q}_{A}^{\prime \prime \prime}$ is the actual heat release per unit volume equal to $1110 \mathrm{~kW} / \mathrm{m}^{3}$ for parallel panel flames. Using Eq. 4 define the dimensionless flame height

$$
\varsigma_{f}=\ell_{f} / w=\dot{Q}_{A} / \dot{q}_{A}^{\prime \prime \prime} w^{2} d .
$$

The area of the panels in direct contact with the flames is

$$
A_{p}=2 w \ell_{f}=2 w^{2} \varsigma_{f} .
$$


This is the panel area that receives heat flux. The total bounding area of the flame is

$$
A_{T}=2 w \ell_{f}+2 d \ell_{f}+2 w d=2 w^{2}\left(\varsigma_{f}+\alpha \varsigma_{f}+\alpha\right)
$$

The mean beam length of radiation rays coming from the flame volume is

$\ell_{m}=\frac{3.6 V_{f}}{A_{T}}=\frac{3.6 \ell_{f} w d}{2 w^{2}\left(\varsigma_{f}+\alpha \varsigma_{f}+\alpha\right)}=\frac{1.8 d \varsigma_{f}}{\varsigma_{f}+\alpha \varsigma_{f}+\alpha}$.

Using this mean beam length, the heat flux incident on the panel walls is

$$
q_{f}^{\prime \prime}=\sigma T_{f}^{4}\left(1-e^{-\kappa_{f} \ell_{m}}\right) \cong \sigma T_{f}^{4} \kappa_{f} \ell_{m}=1.8 \sigma T_{f}^{4} \kappa_{f} d \frac{\varsigma_{f}}{\varsigma_{f}+\alpha \varsigma_{f}+\alpha}
$$

where $\kappa_{f}$ is the absorption-emission coefficient of the flame gases. It is assumed here that the flames are optically thin (i.e., $\kappa_{f} \ell_{m}<<1$ ). Within the framework of this simplified model, the net heat transfer to the panels, $\dot{Q}_{p}\left(\dot{q}_{0}^{\prime \prime}\right)$, equals the net heat flux $\left(\dot{q}_{f}^{\prime \prime}-\dot{q}_{0}^{\prime \prime}\right)$ multiplied by the panel area receiving heat flux - namely -- $2 \ell_{f} w$. In dimensionless form the heat transfer becomes

$\varsigma_{p}=\frac{\dot{Q}_{p}\left(\dot{q}_{0}^{\prime \prime}\right)}{\dot{q}_{A}^{\prime \prime \prime} w^{2} d}=\frac{\left(\dot{q}_{f}^{\prime \prime}-\dot{q}_{0}^{\prime \prime}\right) 2 \ell_{f} w}{\dot{q}_{A}^{\prime \prime \prime} w^{2} d}=\left[\frac{3.6 \sigma T_{f}^{4} \kappa_{f}}{\dot{q}_{A}^{\prime \prime \prime}}\right] \frac{\varsigma_{f}^{2}}{\varsigma_{f}+\alpha \varsigma_{f}+\alpha}-\frac{2 \dot{q}_{0}^{\prime \prime} \varsigma_{f}}{d \dot{q}_{A}^{\prime \prime \prime}}$

after using Eqs. 5 and 9.

The expression in square brackets is the radiant fraction of the flames. Its numerator is the radiant emission per unit volume, while its denominator is the actual chemical heat release per unit volume. For buoyant turbulent diffusion flames, burning in air the radiant fraction depends on the flame absorption coefficient $\kappa_{f}=\kappa_{s}+\kappa_{g}$ that has contributions from both soot and gas. As the absorption coefficient increases the effective flame radiation temperature decreases [8], such that, $T_{f}^{4} \kappa_{f} \sim \kappa_{f}^{1 / 4}$. The soot absorption coefficient, $\kappa_{s}$ and smoke yield, $Y_{s}$, are both inversely proportional to the smoke point flame height of the fuel [6]. To model the effect of radiation from the combustion gases, we add a constant $Y_{g}=0.01$ to the soot yield to approximate the radiation for fuels having very little or no soot. In view of the discussion above, we replace the expression in square brackets by $\beta_{1}\left(Y_{s}+Y_{g}\right)^{1 / 4}$ to obtain 
$\varsigma_{p}=\frac{\dot{Q}_{p}\left(\dot{q}_{0}^{\prime \prime}\right)}{\dot{q}_{A}^{\prime \prime \prime} w^{2} d}=\frac{\beta_{1}\left(Y_{s}+Y_{g}\right)^{1 / 4} \varsigma_{f}^{2}}{\varsigma_{f}+\alpha \varsigma_{f}+\alpha}-\frac{2 \beta_{2} \dot{q}_{0}^{\prime \prime} \varsigma_{f}}{d \dot{q}_{A}^{\prime \prime \prime}}$

This result is successfully correlated in Fig. 7 for all five fuels and for heat transfer losses, $\dot{q}_{0}^{\prime \prime}$, equal to 5 and $15 \mathrm{~kW} / \mathrm{m}^{2}$. The constants $\beta_{1}=1.04$ and $\beta_{2}=1.7$ were chosen to yield the best fit of the model to the data. We note here that $\beta_{2}$ is considerably larger than unity because the area over which the flame heat-flux $\dot{q}_{f}^{\prime \prime}$ is greater than $\dot{q}_{0}^{\prime \prime}$ decreases (in addition to $\left(\dot{q}_{f}^{\prime \prime}-\dot{q}_{0}^{\prime \prime}\right)$ decreasing) as $\dot{q}_{0}^{\prime \prime}$ increases.

One gains a physical understanding from Fig. 8. The ratio of ordinate to abscissa

$$
\frac{\varsigma_{p}}{\varsigma_{f}}=\frac{\dot{Q}_{p}\left(\dot{q}_{0}^{\prime \prime}\right)}{\dot{Q}_{A}}=\frac{\beta_{1}\left(Y_{s}+Y_{g}\right)^{1 / 4} \varsigma_{f}}{\varsigma_{f}+\alpha \varsigma_{f}+\alpha}-\frac{2 \beta_{2} \dot{q}_{0}^{\prime \prime}}{d \dot{q}_{A}^{\prime \prime \prime}}
$$

is the net fraction of the actual heat release rate transferred to the panels. From the standpoint of flame heat-transfer, this ratio controls the fire growth process. The first term on the right of Eq. 12 gives the radiant (plus convective) fraction that is incident on the panels. This term depends only on fuel type (i.e., $Y_{s}$ ), dimensionless flame height, $\varsigma_{f}$, and panel aspect ratio $\alpha=d / w$. The second term on the right gives the effect of the heat loss, $\dot{q}_{0}^{\prime \prime}$ and physical scale, $d$, of the parallel panel apparatus. The physical scale of the apparatus shows up only in the second term.

Table 1. Properties of Fuels Used in the Study [9].

\begin{tabular}{|l|c|c|c|}
\hline \multicolumn{1}{|c|}{ Fuel } & & $\chi_{A}[--]$ & $Y_{s}$ [g/g ] \\
\hline Carbon Monoxide & $\mathrm{CO}$ & 1.00 & 0 \\
\hline Ethane & $\mathrm{C}_{2} \mathrm{H}_{6}$ & 0.970 & 0.013 \\
\hline Propane & $\mathrm{C}_{3} \mathrm{H}_{8}$ & 0.950 & 0.024 \\
\hline Propylene & $\mathrm{C}_{3} \mathrm{H}_{6}$ & 0.873 & 0.095 \\
\hline 1,3 Butadiene & $1,3-\mathrm{C}_{4} H_{6}$ & 0.753 & 0.125 \\
\hline
\end{tabular}

\section{CONCLUSIONS}

Flame heights and flame heat-flux distributions are measured for a wide range of fuels burning between two parallel panels. The flame heat fluxes are sensitive to fuel sootiness. The flame height measurements imply an actual heat release rate per unit flame volume equal to, $\dot{q}_{A}^{\prime \prime \prime}=1110 \mathrm{~kW} / \mathrm{m}^{3}$, consistent with literature values. The results lead to a simple engineering model for the overall net flame heat transfer to the panels in a parallel panel configuration. The model assumes the flame heat transfer occurs primarily by radiation and that the flames are optically thin. It is then fitted to the data. 


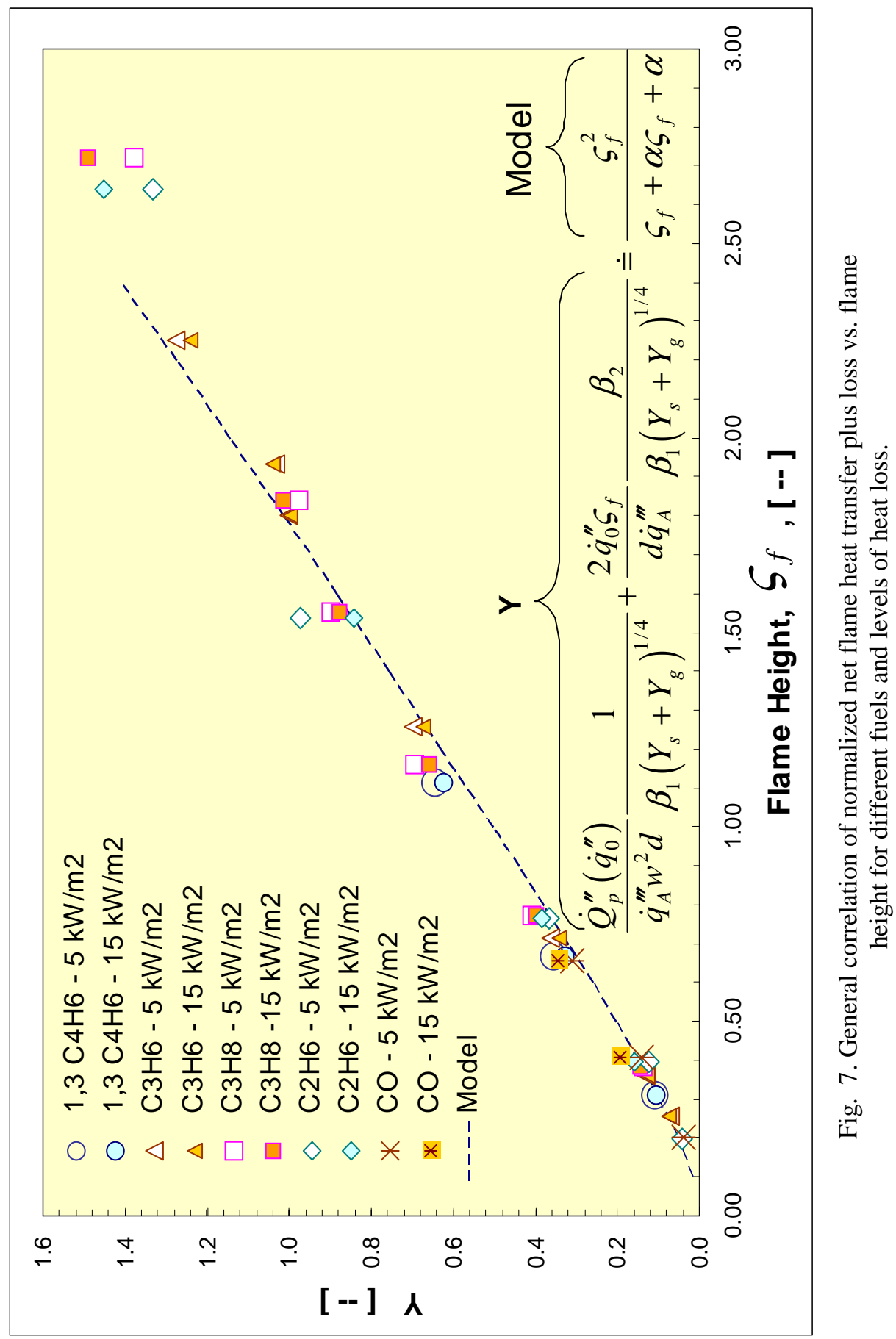




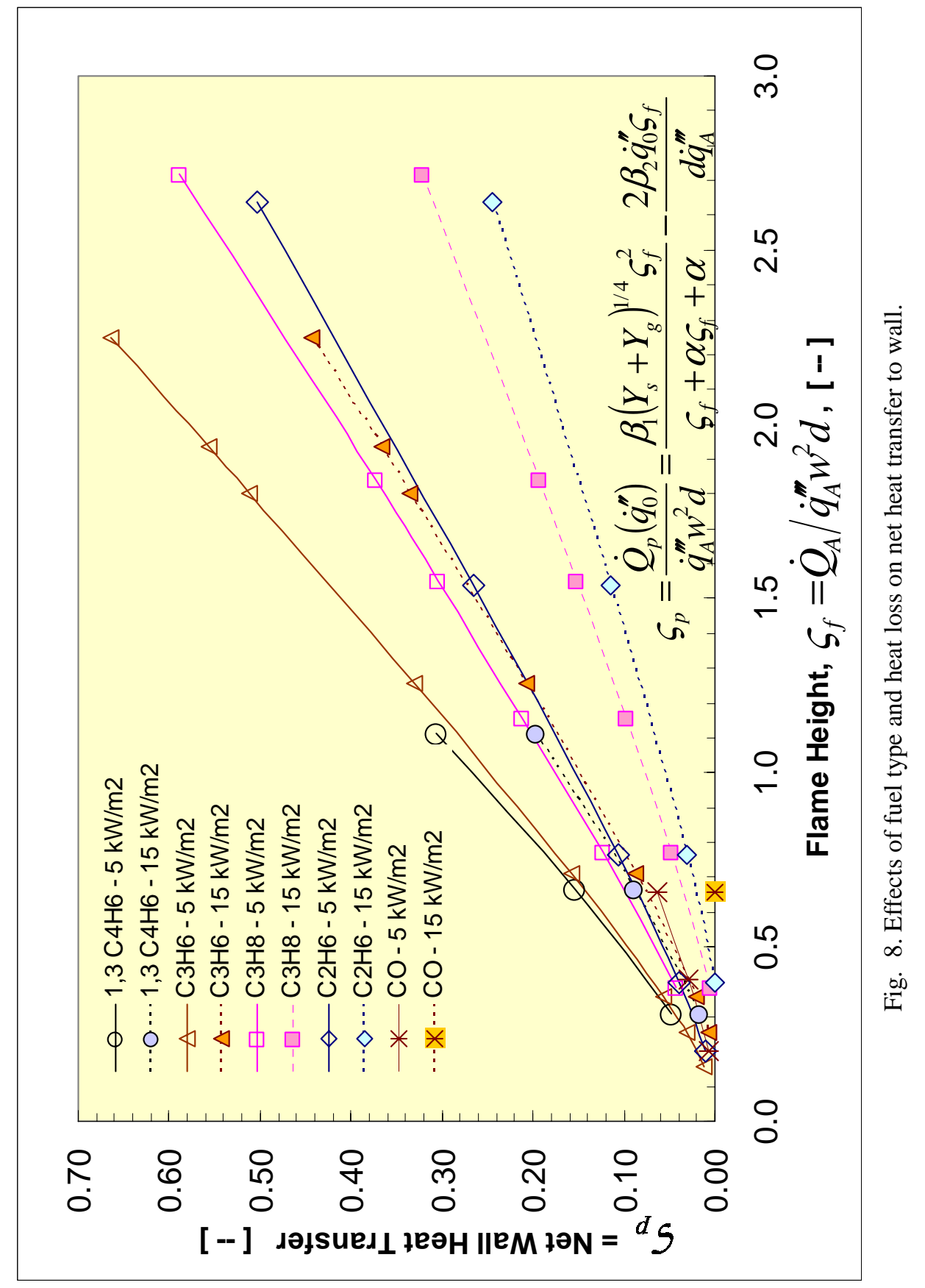


The model is specifically tailored for inclusion into future fire growth models based on laboratory measurements of material properties. It exploits the observed proportionality between flame volume and heat release rate. The semi-empirical model is quite general. It expresses the net heat transfer to the walls, $\dot{Q}_{p}$ in terms of: (1) actual chemical heat release rate, $\dot{Q}_{A}=\chi_{A} \dot{Q}_{T}$ of the fire, (2) parallel panel dimensions -- width, $w$, and separation, $d$, (3) flame sootiness, expressed by the smoke yield, $Y_{s}$, of the material and gas equivalent smoke yield, $Y_{g}$, as well as the (4) surface heat loss rate, $\dot{q}_{0}^{\prime \prime}$ due to reradiation from the wall material being tested.

\section{ACKNOWLEDGEMENTS}

The authors wish to express their gratitude to Dr.'s Robert G. Bill, Peter K. Wu and FM Global for their continuing enthusiastic support of this work.

\section{REFERENCES}

[1] "FM Approvals, Cleanroom Materials, Flammability Test Protocol,” Class Number 4910, FM Approvals, 1151 Boston-Providence Turnpike, Norwood, Massachusetts, U.S.A., September 1997.

[2] Nam, S., de Ris, J.L., Wu, P.K., and Bill, Jr. R., "From Bench-scale Test Data to Prophecies of Full-scale Fire Test Results: Journey with Parallel Panel Tests," This Symposium.

[3] Ingason, H., de Ris, J.L., "Flame Heat Transfer in Storage Geometries," Fire Safety Journal, 31, pp. 39-60, 1998.

[4] Orloff, L. and de Ris, J., "Froude Modeling of Pool Fires", Proceedings of the Combustion Institute Vol. 19, pp. 885-895, (1982).

[5] Markstein, G.H., and de Ris, J., "Wall Fire Radiant Emission - Part 1: Slot Burner Flames Comparison with Jet Flames," Proceedings of the Combustion Institute, Vol. 23, pp. 1685-1692, (1990).

[6] de Ris, J.L., Wu, P.K., and Heskestad, G., "Radiation Fire Modeling," Proceedings of the Combustion Institute, Vol. 28, pp. 2751-2759, 2000.

[7] Delichatsios, M.A., and Orloff, L., "Effects of Turbulence on Flame Radiation from Diffusion Flames,” Proceedings of the Combustion Institute, Vol. 22, pp.1271-1279, 1998.

[8] Delichatsios, M.A., "Smoke Yields from Turbulent Buoyant Jet Flames," Fire Safety Journal, 20, pp. 299-311, (1993).

[9] Tewarson, A., "Generation of Heat and Chemical Compounds in Fires," Section 3, Chapter 4, SFPE Fire Protection Handbook, (3rd Ed.), NFPA Press, Quincy, MA, 2002, pp. 3-82 to 3-161. 